\title{
Pentacyclic triterpene methyl ethers in recent lacustrine sediments (Lagoa do Caçó, Brazil).
}

Jérémy Jacob ${ }^{\mathrm{a}, *}$, Jean-Robert Disnar ${ }^{\mathrm{a}}$, Mohammed Boussafir ${ }^{\mathrm{a}}$, Ana Luiza Spadano Albuquerque $^{\mathrm{b}}$, Abdelfettah Sifeddine ${ }^{\mathrm{c}}$ and Bruno Turcq ${ }^{\mathrm{d}}$

a Laboratoire de Sédimentation et Diagenèse de la Matière Organique, Institut des Sciences de la Terre d'Orléans (ISTO) - UMR 6113 du CNRS, Université d'Orléans, Bâtiment Géosciences, 45067 Orléans Cedex 2, France.

${ }^{\mathrm{b}}$ Departamento de Geoquimica, Universidade Federal Fluminense, Morro do Valonguinho s/no.24020-007 Niteroi, Rio de Janeiro, Brazil.

c IRD/CNPq, Departamento de Geoquimica, Universidade Federal Fluminense, Morro do Valonguinho s/no. 24020-007 Niteroi, Rio de Janeiro, Brazil.

${ }^{\mathrm{d}}$ UR055, IRD, Centre d'Ile de France, Institut de Recherche pour le Développement, 32 av. Henri Varagnat. 93143, Bondy Cedex, France.

\begin{abstract}
The lipid extracts of sediments collected from the Quaternary filling of a tropical lacustrine series (Lagoa do Caçó, Brazil) were investigated by gas chromatography-mass spectrometry (GC-MS). Various pentacyclic triterpene 3-methyl ethers (PTMEs) were present in the neutral fraction. Comparison of retention times and mass spectra with available standards allowed us

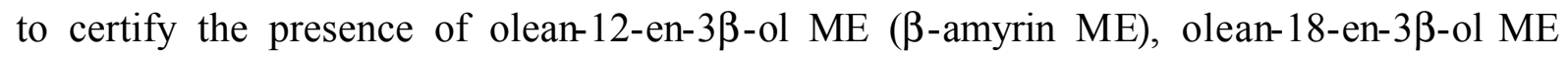
(miliacin), taraxer-14-en-3 $\beta$-ol ME (crusgallin), fern-9(11)-en-3 $\beta$-ol ME (arundoin) and arbor-9(11)-en-3 $\beta$-ol ME (cylindrin). The following other compounds coud also be tentatively identified from their GC-MS characteristics: urs-12-en-3 $\beta$-ol ME, bauer-7-en-3 $\beta$-ol ME and fern-8-en-3 $\beta$-ol ME. Other compounds such as possible $3 \alpha$ isomers of the PTMEs as well as di- or tri- unsaturated counterparts might be PTME diagenetic derivatives. According to previous chemotaxonomic studies, all these compounds most probably originate from Gramineae that used to colonize the savannas of Northern Brazil at the time of deposition.
\end{abstract}

* E-mail address: jeremy.jacob@univ-orleans.fr 


\section{Introduction and setting}

Since the isolation of isoarborinol from the Messel Oil Shale (Albrecht and Ourisson, 1969), the literature has been continuously enriched with information on new pentacyclic triterpenes which have been used in petroleum exploration or paleoenvironmental studies (Cranwell, 1984). These compounds comprise higher plants triterpenes (e.g. oleanane, lupane, ursane derivatives) which occur widely in the plant kingdom in the free form or bound to glycosyl or phenolic moieties through a functional group (Pant and Rastogi, 1979; Das and Mahato, 1983; Mahato et al., 1988; 1992; Mahato and Sen, 1997). The complex molecular skeleton and the different functionality of the triterpenes make this family of compounds one of the most diversified in Nature. Their chemo taxonomic potential, their ability to degrade via specific diagenetic routes and their widespread occurrence in the sedimentary record can provide key information on floral changes and early diagenesis (e.g. Killops et al., 1995). As noted by van Aarssen et al. (2000), few studies have screened for these compounds or their diagenetic derivatives in order to reconstruct past environmental changes and climatic fluctuations. Other relevant work was limited to assessing terrestrial input versus phytoplankton organic matter production(Peters and Moldowan, 1993).

Recent tropical lacustrine sedimentary records are usually poorly described with regard to their biomarker content. Nevertheless, they provide unique botanical and geological records which encourage the identification of new compounds. In addition, studies on biomarkers in these areas could reveal useful information for calibrating geochemical studies on older sediments deposited in similar settings.

Lagoa do Caçó is a small oligotrophic lake located in northeast Brazil, close to the Equator (Fig. 1). The sedimentary filling has been studied using various approaches to better document palaeoclimatic development since the Last Glacial Maximum (LGM) in the Tropics (Ledru et al., 2001; 2002; Sifeddine et al., 2003; Jacob, 2003; Jacob et al., 2004a and b). Here we report on the GC-MS characteristics of several series of pentacyclic triterpene methyl ethers (PTMEs) that are present in the lipid extracts of Quaternary sediments from this tropical setting and their significance as plant source indicators or diagenetic indicators.

\section{Materials and methods}

\subsection{Sediment samples}

The context and sample handling have been described (Jacob et al., 2004a). Briefly, a core (MA98-3; $6 \mathrm{~m}$ long) was divided into two main intervals. The lower one (ca. $3 \mathrm{~m}$ long), which dates back to the end of the LGM, consists of fine-grained sands and silts. The upper 
half (ca. $3 \mathrm{~m}$ long), consisting of organic matter-rich silts, is divided into greenish-brown organic silts (Late Glacial) and black organic silts (Holocene). Two samples, which best illustrate the distribution of PTMEs, were selected following sedimentology and Rock-Eval 6 screening. Sample 170 (352 cm depth) belongs to a section dated back to the LGM, whereas sample 073 (150 cm depth) is from sediments deposited during the Holocene.

\subsection{Extraction and separation of free lipids}

The method for lipid extraction and separation was based on that of Logan and Eglinton (1994), with some modifications. One gram of dried sediment was ultrasonically extracted with acetone-pentane 1:1. The mixture was then separated into a neutral and an acidic fraction by solid phase extraction using AminoPropyl Bond Elute $C$ cartridges. Neutral compounds were eluted with $\mathrm{DCM}: \mathrm{CH}_{3} \mathrm{OH}(1: 1)$ and acidic compounds with ether after acidification of the medium with ether:formic acid 9:1. The neutral fraction was submitted to further fractionation on activated Florisil ${ }^{\circledR}$ to give aliphatic hydrocarbons (eluted with heptane), aromatic hydrocarbons and ethers (DCM) and polar compounds (DCM:CH $\mathrm{CH}_{3} \mathrm{OH}$ 1:1).

\section{3. $G C-M S$}

GC-MS analysis was performed on a ThermoFinnigan TRACE-PolarisGCQ gas chromatograph-mass spectrometer. The gas chromatograph was fitted with an Rtx ${ }^{\circledR}-5$ Sil MS capillary column (30 m x $0.32 \mathrm{~mm}$ i.d., $0.25 \mu \mathrm{m}$ film thickness) with $5 \mathrm{~m}$ of guard column. The GC operating conditions were as follows: temperature hold at $40^{\circ} \mathrm{C}$ for $1 \mathrm{~min}$, then increase from 40 to $120^{\circ} \mathrm{C}$ at $30^{\circ} \mathrm{C} \cdot \mathrm{min}^{-1}, 120$ to $300^{\circ} \mathrm{C}$ at $3^{\circ} \mathrm{C} \cdot \mathrm{min}^{-1}$ with final isothermal hold at $300^{\circ} \mathrm{C}$ over $30 \mathrm{~min}$. The sample was injected splitless, with the injector temperature set at $280^{\circ} \mathrm{C}$. Helium was the carrier gas. The mass spectrometer was operated in the electron ionisation(EI) mode at $70 \mathrm{eV}$ ionization energy and scanned from 50 to 650 Dalton. Where possible, the structure of individual compounds was ascertained with authentic standards isolated from extant plants that were analysed with the same conditions. The remaining compounds were tentatively identified by comparison of mass spectra with literature data, relative retention times and interpretation of mass spectrometric fragmentation patterns.

\section{Results}

Total extract yields ranged between 0.5 and $4.2 \mathrm{mg} . \mathrm{g}^{-1}$ sediment. The neutral fraction afforded between 0.4 and $3.5 \mathrm{mg} . \mathrm{g}^{-1}$ sediment. The dominant compounds in this fraction are PTMEs and hopanoids. In total, at least sixteen compounds were distinguished by GC-MS. Two 
examples of the distribution of these compounds in two extracts from the sedimentary fill of Lagoa do Caçó are shown in Fig. 2 together with a reconstructed total ion current (TIC) trace of reference compounds.

In total, five out of the sixteen compounds were identified by coelution with available standards, the identification of other compounds remaining tentative. The main characteristics of all the studied compounds are summarized in Table 1. Thirteen out of the sixteen have a molecular mass of 440 amu (Table 1). Compared to these compounds, two others with a molecular mass of 438 and another with 436, most probably have one and two additional double bonds, respectively. For most of the compounds having a molecular mass of $440 \mathrm{amu}$, the presence of fragments at $m / z 408\left[(\mathrm{M}-32)^{+}\right]$and $m / z 393[(\mathrm{M}-15)-32]^{+}$points to the loss of a methoxy group as a neutral methanol molecule during fragmentation (Bryce et al., 1967b). These characteristics, plus the fragmentation pattern typical for triterpene ethers as discussed below, led us to propose that the compounds with a molecular mass of 440 are unsaturated methoxy triterpenes having the formula $\mathrm{C}_{31} \mathrm{H}_{52} \mathrm{O}$. At first sight the compounds can be separated into two main groups, namely those whose mass spectra are dominated by fragments at $m / z 218,203 / 204$ and 189 (compounds 2-7) and those giving a base peak at $m / z$ 273 and a major fragment at $m / z 241$ (compounds 8, 10, 13, 14 and 15). We discuss first the possible identity of the compounds belonging to these two different groups, then, we consider those having different general characteristics (compounds 1, 9, 11, 12 and 16).

\subsection{Compounds 2 to 7}

The intense fragments at $m / z 218,203 / 204$ and 189 in the mass spectra of compounds 2 to 7 (Fig. 3) can arise from the D/E moiety of normal and D-friedo- triterpenes after C-ring breaking and possible retro-Diels Alder rearrangement (Budzikiewicz et al., 1962; Djerassi et al., 1962).

In addition to intense ions at $\mathrm{m} / z$ 218, 204 and 189, the mass spectra of compounds 2 and 4 (Fig. 4) also show intense fragments at $m / z$ 316, 301, 284 and 269 typical for taraxer-14-en$3 \beta$-ol methyl ether (i.e. sawamilletin or crusgallin; Bryce et al., 1967a). As a matter of fact, comparison of retention time and mass spectrum with an authentic standard allowed us to identify compound 4 as taraxer-14-en-3 $\beta$-ol ME (Fig. 4). Compound 2 has a comparable mass spectrum to compound 4 except for the fragment at $\mathrm{m} / \mathrm{z} 190$, which could arise from hydrogen rearrangement on the $\mathrm{m} / \mathrm{z} 189$ moiety or from a possible coeluting compound. Because only the mass spectrum of taraxer-14-en-3-ol ME is presently known to display fragments at $m / z$ $316,301,284$ and 269 , it can thus be supposed that compound 2 could correspond to the 
taraxer-14-en-3-ol methyl ether isomer evidenced by Bryce et al. (1967a). The simplest change that taraxer-14-en-3 $\beta$-ol ME (compound 4) could undergo, without significantly affecting the fragmentation pattern, is an epimerisation of the methyl ether group, at the C-3 position. We can therefore hypothesize that compound 2 is taraxer-14-en-3 $\alpha$-ol ME.

Co-injection with an authentic standard (Fig. 3) allowed us to identify compound 6 as olean12-en-3 $\beta$-ol ME ( $\beta$-amyrin ME or isosawamilletin; Fig. 5). In a similar way as for compounds 2 and 4 discussed above, the difference in retention time and spectral resemblance between compounds 3 and 6 (Fig. 5) led us to hypothesize that compound 3 could be the $3 \alpha$ - epimer of compound 6, i.e. olean-12-en-3 $\alpha$-ol ME.

In the absence of an available standard but according to mass spectral resemblance (Bryce et al., 1967b), compound 5 is tentatively identified as urs-12-en-3 $\beta$-ol ME ( $\alpha$-amyrin ME; Fig. 5). Identical retention time (Fig. 3) and mass spectrum with an authentic standard allowed us to identify compound 7 as olean-18-en-3 $\beta$-ol ME(miliacin or germanicol ME; Fig. 6).

\subsection{Compounds $8,10,13,14$ and 15}

Compounds 8, 10, 13, 14 and 15 (Fig. 7) display very similar mass spectral features, with significant fragments at $\mathrm{m} / \mathrm{z} 393,287,273,255$ and 241 in comparable proportions in the five spectra (Fig. 8). The dominant fragment at $m / z 273$ [M-167] $]^{+}$is typical of D:C- or E:C-friedo triterpenes of the fernane, arborane, bauerane, or multiflorane type (Nishimoto et al., 1968; Shiojima et al., 1992). By loss of $\mathrm{CH}_{3} \mathrm{OH}$, this latter fragment produces the other important fragment at $\mathrm{m} / \mathrm{z}$ 241. A small fragment at $\mathrm{m} / \mathrm{z} 365$ could be attributed to the loss of an isopropyl group from the $\mathrm{m} / \mathrm{z} 408\left[(\mathrm{M}-32)^{+}\right]$fragment. Therefore, compounds 8, 10, 13, 14 and 15 can be identified as D:C- or E:C-friedo triterpene methyl ethers with an isopropyl group on ring $\mathrm{E}$ and a double bond in the $\Delta^{9(11)}$ or $\Delta^{8}$ positions (Nishimoto et al., 1968; Bryce et al., 1967a). By comparison of retention times (Fig. 7) and mass spectra with authentic standards, compounds 14 and 15 can be identified as fern-9(11)-en-3 $\beta$-ol ME (arundoin) and as arbor-9(11)-en-3 $\beta$-ol ME (cylindrin), respectively (Fig. 8).

Finally, there are few spectroscopic features to distinguish between the three remaining compounds $(8,10$ and 13$)$. In the same way as for taraxer-14-en-3 $\beta$-ol ME (compound 4) and its possible $3 \alpha$ epimer (compound 2) discussed above, comparable differences in retention time between compounds $8-14$ and $10-15$ (1.51 $\mathrm{min}$ and $1.78 \mathrm{~min}$, respectively) and mass spectral resemblances lead us to propose that compounds 8 and 10 could be the $3 \alpha$-epimers of fern-9(11)-en-3-ol ME and arbor-9(11)-en-3-ol ME, respectively. The remaining 
compound 13 could be the fern- 8 -en- $3 \beta$-ol ME, previously described by Nishimoto et al. (1968).

\subsection{Compounds 11 and 1}

Compound 11 coelutes with compound 10 under the GC temperature program used routinely (Fig. 7). The mass spectra of 10 and 11 were obtained on samples containing greater proportions of one of these two compounds than of the other, and by background subtraction. The mass spectrum of 11 is dominated by a strong doublet at $m / z 261$ and $m / z 229$ (Fig. 9). Small fragments at $\mathrm{m} / \mathrm{z} 273$ and $\mathrm{m} / \mathrm{z} 241$ may originate from the coeluting compound 10 (Fig. 7). No fragment indicative of the loss of an isopropyl group from the ion at $\mathrm{m} / \mathrm{z} 408$ was detected. From this evidence and according to Nishimoto et al. (1968) and Bryce et al. (1967b), compound 11 is tentatively identified as bauer-7-en-3 $\beta$-ol ME.

Compound 1 (Fig. 3) shows a mass spectrum with a base peak at $m / z 163$ and intense ions at $m / z 191$ and $m / z 205$ (Fig. 10). Minor doublets at $m / z 229$ and 261, $m / z 241$ and 273, $m / z 255$ and 287 and $m / z 323$ and 355 suggest a D:C - or E:C - friedo structure with a methoxy group on ring A. Ions at $\mathrm{m} / \mathrm{z} 365$ and $\mathrm{m} / \mathrm{z} 163$ indicate the loss of an isopropyl group from fragments at $\mathrm{m} / \mathrm{z} 408$ and 206, respectively. The relatively short retention time of compound 1 could be indicative of a tetracyclic triterpene methyl ether. However, significant differences in retention times or fragmentation patterns, exclude the possibility that compound 1 could be cycloartenol ME (Fig. 3), or parkeol ME (Russell et al., 1976), respectively. Because lanostene-type molecules have a similar fragmentation behaviour as that of arborenes/fernenes (ascribed to the presence of methyl groups located at the C/D-ring junction), compound 1 is tentatively assigned as a lanostadienol ME (Fig. 10; Uyeo et al., 1968).

\subsection{Compounds 9,12 and 16}

The spectra of compounds 9 and 12 have comparable features: a molecular ion at $\mathrm{m} / \mathrm{z} 438$, fragments at $m / z 423[\mathrm{M}-15]^{+}$, and $m / z 391$ [(M-15)-32] $]^{+}$(Fig. 11). Fragments at $m / z 425$ and 408 in the mass spectra of compound 9 arise from coeluting compound 8 . The fragment at $\mathrm{m} / \mathrm{z}$ 363 can be explained by loss of an isopropyl group from ion $\mathrm{m} / z$ 406, well expressed in the spectra of 12. The spectra of both compounds exhibit doublets at $m / z 285$ and 253 and 271 and 239, indicative of an additional double bond on A, B or C-ring as compared with the spectra of compounds 8, 10,13,14 and 15 (Fig. 8). Accordingly, 9 and 12 are thought to be di-unsaturated D:C- or E:C-friedo PTMEs with a fernane or arborane skeleton. Given the 
earlier elution of fernane-type compared to arborane-type compounds, we propose a ferna7,9(11)-dien-ol ME structure for 9 and an arbora-7,9(11)-dien-ol ME structure for 12.

Compound 16 (Fig. 7) has a molecular ion at $\mathrm{m} / \mathrm{z}$ 436, which is consistent with a structure of PTME with three double bonds (Fig. 11). Its mass spectrum points to a D:C- or E:C-friedo structure. Comparison with the spectra of compounds 9 and 12 (Fig. 11) suggests that the additional double bond is located on ring A or B. From this evidence, an arboratriene or fernatriene ME structure is proposed for compound 16.

\section{Discussion}

To our knowledge, the only previous record of methoxy triterpenes in geological samples was made by Ries-Kautt (1986), who identified in soils one compound displaying a similar mass spectrum to fern-9(11)-en-3 $\beta$-ol ME and another unidentified one that could be related to taraxer-14-en-3 $\beta$-ol ME.

\subsection{Biological sources of PTMEs}

The following discussion on PTME biological sources is mainly based on available information on the occurrences of these compounds in living organisms and on a comparison with those detected from Lagoa do Caçó (Table 2). Pentacyclic triterpenes bearing an oxygenated group at position 3 are widely distributed in the plant kingdom (Pant and Rastogi, 1979; Das and Mahato, 1983; Mahato et al., 1988; 1992; Mahato and Sen, 1997). Nevertheless, methyl ethers are rather uncommon. Most of the PTME plant sources are monocots and belong to Gramineae (Poaceae). PTMEs from Gramineae have been largely studied during the 1960s (review in Martin-Smith et al., 1967; Ohmoto et al., 1970). Ohmoto et al. (1970) reported on the occurrence of nine PTME structures from thirty one species of Gramineae belonging to fourteen tribes. Little chemotaxonomic evidence is available from these studies due to the few plants studied. More recently, arbor-9(11)-en-3 $\beta$-ol ME, lupanol ME and lupeol ME have been identified in palm trees (Butia capitata and Orbignya sp.; Garcia et al., 1995; Elaeis guineensis; Goh et al, 1988). Taraxer-14-en-3 $\beta$-ol ME, arbor9(11)-en-3 $\alpha$-ol ME and arbor-9(11)-en-3 $\beta$-ol ME have also been isolated from various dicots

(Diospyros ferrea, Bosistoa sp. and Mimusops littoralis; Deshmane and Dev, 1971). Finally, Pinaceae (Rowe and Bower, 1965) and Burseraceae (Uyeo et al., 1968) have been cited as sources of PTMEs but, in the case of Pinaceae, the compounds were of the serratane-type. Injection of authentic lupeol ME (Bryce et al., 1967a) proves its absence in the analysed 
samples (Fig. 2). In addition, none of the following compounds have been detected in our samples: hop-22(29)-en-3 $\beta$-ol ME (Rowan and Russell, 1992; Paupit et al., 1984), friedelenol ME (Oros and Simoneit, 2001) and serratenol ME (Rowe and Bower, 1965).

It is clear from the data in Table 2 that none of the species cited in the literature affords a range of PTMEs as wide as that encountered in our samples. Fern-9(11)-en-3 $\beta$-ol ME, arbor-

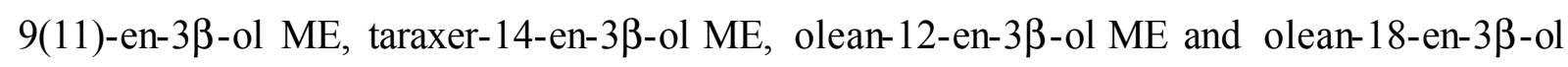
ME only co-occur in Poaceae species. The taxon displaying the distribution of PTMEs which is the more comparable to that found in our samples is Andropogonae. As a matter of fact, plants belonging to this genus produce taraxer-14-en-3 $\beta$-ol ME, olean-18-en-3 $\beta$-ol ME, fern-

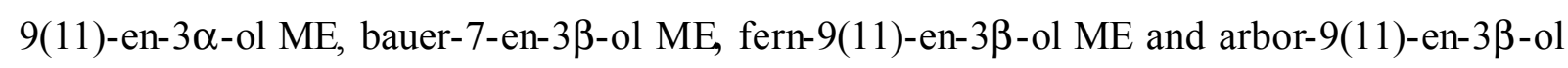
ME but not olean-12-en-3 $\beta$-ol ME. Therefore, although Andropogonae could appear as a likely source for the sedimentary PTMEs, at least one additional source must also be envisaged. While screening chemotaxonomic relationships in the Cortaderiae genus, MartinSmith et al. (1967) noted that the South American strains (C. selloana and C. atacamensis) did not contain any PTMEs, in contrast to New Zealand species. It must thus be considered that the biological precursor(s) of the PTMEs identified in our samples could also originate from at least one of the twenty Cortaderiae species that have not been analysed yet.

\subsection{Diagenesis of PTMEs}

PTMEs are minor components in living organisms and are defined as secondary metabolites (H. Connor, pers. comm.). These compounds are found in leaf epicuticular waxes, where they play a crucial role in defending the organism against external agents (e.g. microbes, fungi, U.V). In the upper section of Lagoa do Caçó sediments (i.e. since the Late Glacial), the OM is dominantly terrestrial in origin and is subjected to strong reworking in aerobic waters (Jacob, 2003; Jacob et al., 2004a). Therefore, the relatively high abundance of PTMEs in the core section, is probably due to their relative resistance to early degradation processes and hence a better preservation than many other biomarkers.

Despite this relative resistance, PTMEs could undergo alteration to their structure that might account for the enhanced diversity observed in the sediments of Lagoa do Caçó, as compared to the reported occurrences in the plant kingdom.

Pentacyclic triterpenes are known to undergo structural rearrangements (Courtney et al., 1958; Coates, 1967; Chatterjee et al., 1976; Ageta et al., 1987; Rullkötter et al., 1994). For example, ten Haven et al. (1992) have shown that taraxerane-type structures are converted into 
thermodynamically more stable oleanane-type compounds. Similarly, Ageta et al. (1987) have demonstrated that fern- $9(11)$-ene is converted into fern-8-ene when treated with $\mathrm{BF}_{3}$. The presence of olean-12-en-3 $\beta$-ol ME, together with olean-18-en-3 $\beta$-ol ME in the sediments of Lagoa do Caçó could hence result from the diagenetic rearrangement of taraxer-14-en-3 $\beta$-ol ME. Similarly, the supposed fern- 8 -en-3 $\beta$-ol ME could be produced from fern- $9(11)$-en-3 $\beta$-ol ME.

Although the presence of $3 \alpha$ - isomers in the sediments of Lagoa do Caçó remains speculative, it constitutes the simplest way to explain the diversity of PTMEs present in the sediment, especially with regard to their known occurrences in the plant kingdom. Few $3 \alpha$-PTMEs have been isolated from living sources (Table 2). Arborinol ME (arbor-9(11)-en-3 $\alpha$-ol methyl ether) was isolated from thirteen plant species and fern-9(11)-en-3 $\alpha$-ol methyl ether from two plant species, $3 \alpha$-friedelin methyl ether has been found in leaves of Humboldtia laurifolia (Samaraweera et al., 1983) and was suspected in aerosols from burnings of Tsuga mertensiana (Oros and Simoneit, 2001). If demonstrated, the presence of several $3 \alpha$ - PTMEs in Lagoa do Caçó sediments would suggest a process of epimerisation during diagenesis. Such a possibility is supported by the observations of Bryce et al. (1967a) on the possible isomers of arundoin and sawamilletin. Acid catalysed epimerisation at position 3 of pentacyclic triterpenes is well known for alcohols (e.g. arborinol/isoarborinol: Pakrashi and Samanta, 1967; friedel-8-en-3 $\beta$-ol/ friedel-8-en-3 $\alpha$-ol: Chatterjee et al., 1976). Although there is no report of $\beta$ to $\alpha$ isomerisation for PTMEs, this transformation could occur at the C-3 position, especially in an acidic medium (G. Eglinton, pers. comm.). It can be hypothesized that this process is promoted by microbial activity or mineral catalysis as in the case for alcohols (ten Haven et al., 1992). As a matter of fact, the decrease in the taraxer-14-en-3 $\beta$-ol / taraxer-14-en-3 $\alpha$-ol ratio along the whole core suggests a precursor/byproduct relationship and the conversion from $3 \beta$ to $3 \alpha$ configuration during early diagenesis (Jacob, 2003).

Bryce et al. (1967a) reported three synthetic di-unsaturated PTMEs, namely multiflor-7,9(11)-

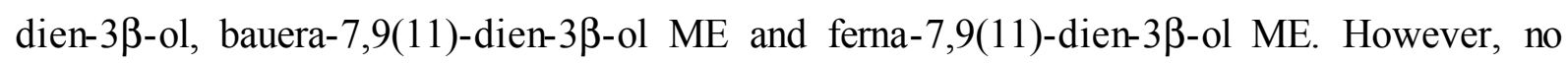
natural di- or tri-unsaturated PTME having been reported yet, compounds 9, 12 and 16 could then merely correspond to early diagenetic products deriving from mono- unsaturated PTMEs rather than be biological constituents.

\subsection{Implications for paleoenvironmental and phytochemical studies}


Paleoenvironmental reconstructions in tropical continental series are often focussed mostly on the alternation of savannas and forests that document climate change from dry to humid and conversely. Contrary to pollens that record vegetation from a rather large surrounding area, biomarkers can certify autochthonous production at the site of deposition or, at least, within the catchment area. Furthermore, the homogeneity in morphology of South American pollens from Gramineae (Salgado-Labouriau, 1997) prevents distinction between ecologically significant species, genus or families. Carbon isotopic $\left(\delta^{13} \mathrm{C}\right)$ and lignin analyses, which have been used to distinguish between savannas and forests (Guillet et al., 2000), were performed on bulk OM and thus did not offer the possibility of tracking ecologically significant species or genus as PTMEs might probably do. Some other key information could be gained from these biomarkers. As noticed above, they seem to be resistant to degradation and may therefore be preserved even under highly degrading conditions, as opposed to Gramineae pollens that are easily destroyed (Ledru, pers. comm.).

Another field of investigation concerns the ecological role of PTMEs. Ohmoto et al. (1970) pointed out that the PTME content of Cortaderiae changes with season, probably as a consequence of a given physiological function of these compounds in plants. This assumption is also evidenced in Zoysieae, where arundoin dominates in inland species while sawamilletin dominates in plants growing on sandy seashores. Although the physiological role of PTMEs is not fully understood, their relative abundance in epicuticular waxes of a given species suggests that they could represent a response to environmental stress. As noticed by MartinSmith et al. (1967), the co-occurrence of different PTME skeletons implies the existence of several types of oxido-squalene cyclases and methyl transferases in parent plants. The involvment of these enzymes, and thus, PTMEs synthesis, could be controlled by environmental stress. Finally, it is worthwhile noting that, while biochemicalphytochemical investigations are the main sources of information on plant-biomarker relationships in organic geochemistry, the detection of PTMEs in Lagoa do Caçó sediments might be a prelude o the discovery of yet unknown South American PTME plant producers.

\subsection{Fernane and arborane type compounds in the sedimentary record}

The origin of fernane and arborane derivatives in sedimentary series is still a matter of debate. Arborinone and isoarborinol have been identified together with des-A-arborenes in Lake Valencia sediments (Jaffé and Hausmann, 1995). Ourisson and Rohmer (1982) assumed a microbial origin for these compounds. This assumption was later supported by stable carbon isotopic data that were consistent with an algal origin (Hauke et al., 1992). Components of 
these molecular groups that have been recorded up to the Upper Carboniferous (Vliex et al., 1994) have been assigned a higher plant origin. This was consistent with the initial hypothesis of Albrecht and Ourisson (1969). Our findings provide further support to this interpretation and suggest that Gramineae might be an important source of fernane and arborane-type compounds in the sedimentary record.

\section{Conclusion}

The Quaternary filling of Lagoa do Caçó afforded a wide range of pentacyclic triterpene methyl ethers. These compounds dominate the neutral solvent-extractable fraction. The identity of five of them has unambiguously been assigned with available reference compounds. Based on an inventory of plants from which PTMEs have already been isolated, Gramineae that grew in the watershed at the time of sediment deposition appear as the most probable sources of these compounds. The presence of PTMEs in Lagoa do Caçó sediments witnesses to their peculiar resistance to degradation. Their structural diversity could result from: (a) a diversified set of plant producers; (b) the ability of an unknown species to produce several compounds; (c) early diagenetic transformation; (d) a combination of these three hypotheses. From a more general point of view, because: (i) of the existence of only few reports of PTMEs in plants (mostly in Gramineae but none from South America); (ii) only two or three Gramineae species dominate savanna ecosystems in the tropics (D. Schwark, pers. comm.), it can be hypothesized that the PTMEs discussed in this study might have been produced by a single species of Gramineae. As a consequence, PTMEs might appear as a unique example of specific higher plant-derived biomarkers.

\section{Acknowledgements}

Pr. R.M. Smith (Loughborough University, UK), Pr. H.E. Connor (University of Canterbury, NZ) and Pr. G. Eglinton (Bristol University, UK) are greatly acknowledged for providing reference compounds and valuable discussions about chemotaxonomy. The authors also wish to thank Pr. G. Bouchoux (Ecole Polytechnique, France), Dr. P. Metzger (Ecole de Chimie de Paris, France) and Pr. B. Simoneit (Oregon State University, US) for useful discussions on mass spectra interpretation. Dr. B. van Aarssen and two anonymous reviewers are also greatly acknowledged for improving the original version of this manuscript. The study has been supported by an IRD (France)-CNPq (Brazil) convention and a CNRS (France)-CNPq (Brazil) convention. One of us (J. Jacob) receives financial support from the Conseil Régional du Centre. 


\section{References}

van Aarssen B.G.K., Alexander R. and Kagi R. I., 2000. Higher plant biomarkers reflect palaeovegetation changes during Jurassic times. Geochimica et Cosmochimica Acta 64, 1417-1424.

Ageta, H., Shiojima, K. et Arai Y., 1987. Acid-induced rearrangement of triterpenoid hydrocarbons belonging to the hopane and migrated hopane series. Chemical and Pharmaceutical Bulletin 35, 2705-2716.

Albrecht P. and Ourisson G., 1969. Triterpene alcohol isolation from oil shale. Science. 163, 1192-1193.

Bryce T.A., Eglinton G., Hamilton R.J., Martin-Smith M. and Subramanian G., 1967a. Triterpenoids from New Zealand plants - The triterpene methyl ethers of Cortaderia toetoe zotov. Phytochemistry 6, 727-733.

Bryce T.A., Martin-Smith M., Osske G., Schreiber K. and Subramanian G., 1967b. Sterols and triterpenoids - Isolation of arundoin and sawamilletin from Cuban sugar cane wax. Tetrahedron 23, 1283-1296.

Budzikiewicz H., Wilson J.M. and Djerassi C., 1962. Mass spectrometry in structural and stereochemical problems. XXXII. Pentacyclic triterpenes. Journal of the American Chemical Society 85, 3688-3699.

Chatterjee A., Mukhopadhyay S. and Chattopadhyay K., 1976. Lewis acid catalysed rearrangement of triterpenoids. Tetrahedron 32, 3051-3053.

Coates, R. M., 1967. On the friedelane-oleanane rearrangement. Tetrahedron Letters 42, 4143-4146.

Courtney, J. L., Gascoigne, R. M. et Szumer, A. Z., 1958. Triterpenoids of the friedelane series. Part III. The course of friedelane-oleanane rearrangement. Journal of the Chemical Society, 881-886.

Cranwell P.A., 1984. Organic geochemistry of lacustrine sediments: triterpenoids of higher plant origin reflecting post-glacial vegetational succession. In: Haworth, E.Y. and Lund, J.W.G. (Eds), Lakes sediments and environmental history. University Press, Leicester. pp. 69-92.

Das M.C. and Mahato S.B., 1983. Triterpenoids. Phytochemistry.22, 1071-1095.

Deshmane S.S. and Dev S., 1971. Higher isoprenoids-II; Triterpenoids and steroids of Saccharum officinarum linn.. Tetrahedron 27, 1109-1118. 
Djerassi C., Budzikiewicz H. and Wilson J.M., 1962. Mass spectrometry in structural and stereochemical problems. Unsaturated pentacyclic triterpenoids. Tetrahedron Letters 3, 263-270.

Garcia S., Heinzen H., Hubbuch C., Martinez R., de Vries X. and Moyna P., 1995. Triterpene methyl ethers from palmae epicuticular waxes. Phytochemistry 39, 1381-1382.

Goh S.H., Lai F.L. and Gee P.T., 1988. Wax esters and triterpene methyl ethers from the exocarp of Elaeis guineensis. Phytochemistry 27, pp.877-880.

Guillet B., Maman O., Achoundong G., Mariotti A., Girardin C., Schwartz D. and Youta Happi J., 2000. Evidences isotopiques et géochimiques de l'avancée de la forêt sur la savane au Cameroun. In: Servant, M. and Servant-Vildary, S. (Eds), Dynamique à long terme des écosystèmes forestiers intertropicaux. UNESCO and IRD publication, Paris. pp. 169-174.

Hauke, V., Graff, R., Wehrung, P., Trendel, J.M., Albrecht, P., Riva, A., Hopfgartner, G., Gülaçar, F.O., Buchs, A. and Eakin, P.A., 1992b. Novel triterpene-derived hydrocarbons of arborane/fernane series in sediments. Part II. Geochimica et Cosmochimica Acta 56, 3595-3602.

ten Haven H.L., Peakman, T.M. and Rullkötter, J., 1992. Early diagenetic transformation of higher-plant triterpenoids in deep-sea sediments from Baffin Bay. Geochimica et Cosmochimica Acta 56, 2001-2024.

Jacob, J., 2003. Enregistrement des variations paléoenvironnementales depuis 20000 ans dans le Nord Est du Brésil (Lac Caçó) par les triterpènes et autres marqueurs organiques. $\mathrm{PhD}$ thesis Université d'Orléans, France. pp. 296. Website: http://tel.ccsd.cnrs.fr/documents/archives0/00/00/29/42/index_fr.html

Jacob J., Disnar J.R., Boussafir M., Sifeddine A., Albuquerque A.L.S. and Turcq B. (2004a). Major environmental changes recorded by lacustrine sedimentary organic matter since the Last Glacial Maximum under the tropics (Lagoa do Caçó, NE Brazil). Palaeogeography, Palaeoclimatology, Palaeoecology 205: 183-197.

Jacob J., Disnar J.R., Boussafir M., Ledru M.-P., Sifeddine A., Albuquerque A.L.S. and Turcq B. (2004b). Onocerane I testimonies to dry climatic events during the Quaternary in the Tropics. Organic Geochemistry, 35: 289-297.

Jaffé R. and Hausmann K.B., 1995. Origin and early diagenesis of arborinone/isoarborinol in sediments of a highly productive freshwater lake. Organic Geochemistry 22, 231-235. 
Killops S.D., Raine J.I., Woolhouse A.D. and Weston R.J., 1995. Chemostratigraphic evidence of higher plant evolution in the Taranaki Basin, New Zealand. Organic Geochemistry 23, 429-445.

Ledru, M.P., Cordeiro, R.C., Dominguez, J.M.L, Martin, L., Mourguiart, P., Sifeddine, A. and Turcq, B., 2001. Late-glacial cooling in Amazonia as inferred from pollen at Lagoa do Caçó, Northern Brazil. Quaternary Research 55, 47-56.

Ledru M.P., Mourguiart P., Ceccantini G., Turcq B. and Sifeddine A., 2002. Tropical climates in the game of two hemispheres revealed by abrupt climatic change. Geology 30, 275 278.

Logan, G.A. and Eglinton, G., 1994. Biogeochemistry of the Miocene lacustrine deposit, at Clarkia, northern Idaho, U.S.A. Organic Geochemistry 21, 857-870.

Mahato S. B., Nandy A. K. and Roy G., 1992. Triterpenoids. Phytochemistry 9, 2199-2249.

Mahato S.B., Sarkar S.K. and Poddar S.G., 1988. Triterpenoid saponins. Phytochemistry 27, 3037-3067.

Mahato S.B. and Sen S., 1997. Advances in triterpenoid research 1990-1994. Phytochemistry 44, 1185-1236.

Martin-Smith M., Subramanian G. and Connor H.E., 1967. Surface wax components of five species of cortaderia (Gramineae) - A chemotaxonomic comparison. Phytochemistry 6, 559.

Nishimoto K., Ito M., Natori S. and Ohmoto T., 1968. The structures of arundoin, cylindrin and fernenols. Triterpenoids of fernane and arborane groups of Imperata cylindrical var. koenigii. Tetrahedron 24, 735-752.

Ohmoto T., Ikuse M. and Natori S., 1970. Triterpenoids of the Gramineae. Phytochemistry 6, 559.

Oros D.R. and Simoneit B., 2001. Identification and emission factors of molecular tracers in organic aerosols from biomass burning. Part 1. Temperate climate conifers. Applied Geochemistry 16, 1513-1544.

Ourisson, G. and Rohmer, M., 1982. Prokaryotic polyterpenes: Phyllogenetic precursors of sterols. Current Topics in Membrane Transport 17, 153-182.

Pakrashi, S.C. and Samanta T.B., 1967. Acid induced epimerisation and rearrangements of Arborinol, the novel triterpene from Glycosmis arborea. Tetrahedron Letters 38, 36793684 .

Pant P. and Rastogi R.P., 1979. The triterpenoids. Phytochemistry 18, 1095-1108. 
Paupit R.A., Waters J. M., Rowan D.D., Russell G.B., Connor H.E. and Purdie A.W., 1984.

The Structure of 19aH-Lupeol Methyl Ether from Chionochloa bromoides. Australian Journal of Chemistry 37, 1341-1347.

Peters K. E. and Moldowan J. M., 1993. The biomarker guide. Prentice Hall.

Ries-Kautt, M., 1986. Etude des lipides dans divers types de sols. Aspects Moléculaires. PhD thesis. Université Louis Pasteur de Strasbourg. 152p.

Rowan D. D. and Russell G. B., 1992. 3ß-methoxy-hop-22(29)-ene from Chionochloa cheesmanii. Phytochemistry 31, 702-703.

Rowe J.W. and Bower C.L., 1965. Triterpenes of Pine barks: Naturally occurring derivatives of serratenediol. Tetrahedron Letters 32, 2745-2750.

Rullkötter, J., Peakman, T.M. et ten Haven, H.L, 1994. Early diagenesis of terrigenous triterpenoids and its implications for petroleum geochemistry. Organic Geochemistry $21,215-233$.

Russell G.B., Connor H.E. and Purdie A.W., 1976. Triterpene methyl ethers of Chinochloa (Gramineae). Phytochemistry 15, 1933-1935.

Salgado-Labouriau M.L, 1997. Late Quaternary palaeoclimate in the savannas of South America. Journal of Quaternary Science 12, 371-379.

Samaraweera U., Subramaniam S., Ubais M. and Sultanbawa S., 1983. 3,5,7,3',5'Pentahydroxyflavan and $3 \alpha$-methoxyfriedelan from Humboldtia laurifolia. Phytochemistry 22, 565-567.

Shiojima K., Arai Y., Masuda K., Takase Y., Ageta T. et Ageta H., 1992. Mass Spectra of Pentacyclic Triterpenoids. Chemical and Pharmaceutical Bulletin 40, 1683-1690.

Sifeddine A., Albuquerque A.L.S., Ledru M-P., Turcq, B., Knoppers B., Martin L., Zamboni de Mello W., Passenau H., Landim Dominguez J.M., Campello Cordeiro R., Abrao J.J. and Carlos da Silva Pinto Bittencourt A.C., 2003. A 21000 cal years paleoclimatic record from Caçó Lake, northern Brazil: evidence from sedimentary and pollen analyses. Palaeogeography, Palaeoclimatology, Palaeoecology 189, 25-34.

Uyeo S., Okada J., Matsunaga S. and Rowe J.W., 1968. The structure and stereochemistry of abieslactone. Tetrahedron 24, 2859-2880.

Vliex M., Hagemann H. W. and Püttmann W., 1994. Aromatized arborane/fernane hydrocarbons as molecular indicators of floral changes in Upper Carboniferous/Lower Permian strata of the Saar-Nahe Basin, southwest Germany. Geochimica et Cosmochimica Acta 58, 4689-4702. 


\section{Table:}

Table 1: Mass spectral data for PTMEs.

Table 2: Sources inventory of PTMEs. 


\section{Figure captions :}

Fig. 1: Lagoa do Caçó position and location of the coring site.

Fig. 2: a- Total ion current (TIC) chromatogram in the 55-65min time range of the DCM fraction isolated from two sediment samples from Lagoa do Caçó.

b- Reconstructed TIC chromatogram of available reference compounds.

Fig. 3: a- Specific ion mass chromatograms of DCM fraction isolated from sediments of Lagoa do Caçó.

b- Reconstructed chromatogram from selected fragments of available reference compounds.

Fig. 4: Mass spectra of compounds 2 and 4 and proposed struc tures.

Fig. 5: Mass spectra of compounds 3, 5 and 6 and proposed structures.

Fig. 6: Mass spectrum of compound 7 and proposed structure.

Fig. 7: Specific ion chromatograms illustrating the distribution of D:C- and E:C-friedo PTMEs in Lagoa do Caçó sediments (a: sample 073 and b: sample 170) and (c) reconstructed mass chromatogram of available authentic products.

Fig. 8: Mass spectra of compounds 8, 14, 10, 15 and 13 and proposed structures.

Fig. 9: Mass spectrum of compound 11 and proposed structure.

Fig. 10: Mass spectrum of compound 1 and proposed structure.

Fig. 11: Mass spectra of compound 9, 12 and 16 and proposed structures. Additional double bond (dashed line) in compound 16 can be located either in $\Delta^{2}$ or $\Delta^{15}$ position. 
Table 1

\begin{tabular}{|c|c|c|c|c|}
\hline $\begin{array}{l}\text { Ret. } \\
\text { Time }\end{array}$ & Peak n ${ }^{\circ}$ & Structure & $\mathrm{M}^{+}$ & Most characteristic fragments* \\
\hline 57,59 & 2 & Taraxer-14-en-3 $\alpha$-ol ME & 440 & $425,393,355,316,301,284,269,218(100), 204,190,189,175,159$ \\
\hline 58,4 & 4 & Taraxer-14-en-3 $\beta$-ol & 440 & $425,408,393,355,316,301,284,269,218,204(100), 189,175,159$ \\
\hline 58,68 & 5 & 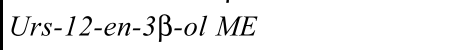 & 440 & $425,408,393,355,255,243,229,218(100), 203,189,175,161$ \\
\hline 58,84 & 6 & Olean-12-en-3 $\beta$-ol ME (b) & 440 & $425,408,393,323,257,243,229,218,204,189(100), 177,161$ \\
\hline 59,87 & 9 & Arbor- or fern-7,9(11)-dien-3-ol ME & 438 & $423,406,391(100), 363,355,323,285,267(100), 253,239,227,213,199,185,171,159$ \\
\hline 60,27 & 10 & Arbor-9(11)-en-3 $\alpha$-ol ME & 440 & $425,408,393,365,273(100), 261,255,241,229,215,201,189,175,163$ \\
\hline 60,27 & 11 & Bauer-7-en-3ß-ol ME & 440 & $425,408,393,273,261(100), 255,241,229,215,201,189,175,163$ \\
\hline 60,6 & 12 & Arbor or fern-7,9(11)-dien-3-ol ME & 438 & $423,406,391,363,321,295(?), 285(100), 271,253,239,225,213,197,183,171,159$ \\
\hline 60,8 & 13 & Fern-8-en-3ß-ol ME & 440 & $425,408,393,365,287,273(100), 261,255,241,229,213,199,187,175,159$ \\
\hline 61,3 & 14 & Fern-9(11)-en-3 $\beta$-ol ME (d) & 440 & $425,408,393,365,355,323,287,273(100), 261,255,241,229,215,201,189,175,159$ \\
\hline
\end{tabular}

Legend: - Ret. time $=$ retention time

- ME = methyl ether

$-\mathrm{M}^{+}=$molecular mass

- (a-e): compound trivial names : (a) sawamilletin or crusgallin; (b) isosawamilletin or b-amyrin ME; (c) miliacin or germanicol ME; (d) arundoin; (e) cylindrin.

- Compounds in bold are those identified with authentic standardss. The identification of the other compounds is only speculative, based on their mass spectral characteristics and retention times.

- * The abundance of the base peak is reported as (100). 


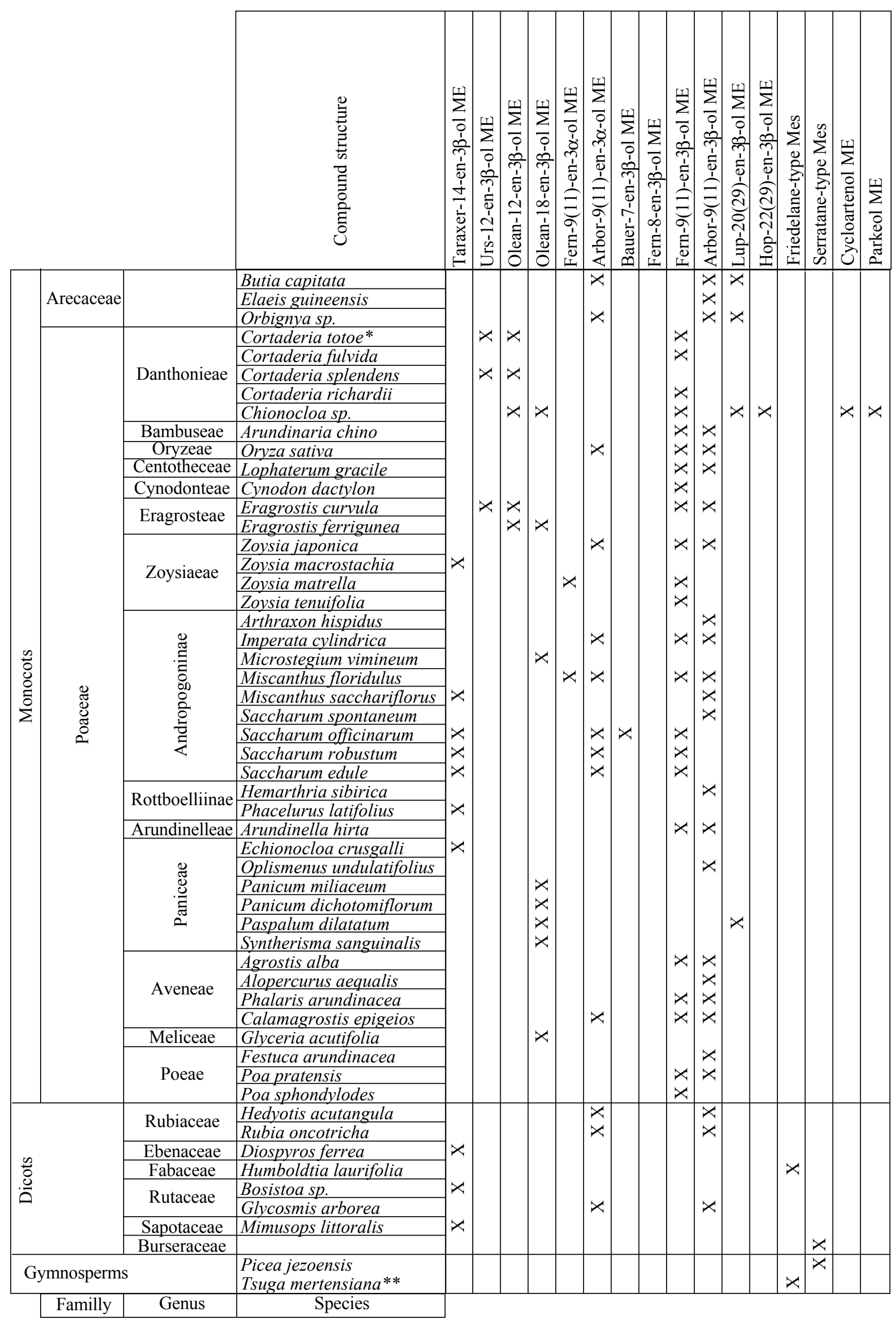

Legend

$\mathrm{X}$ Compound described in taxa

* Cortaderia Totoe is the same species as Arundo conspicua

** Reported in burning aerosols 


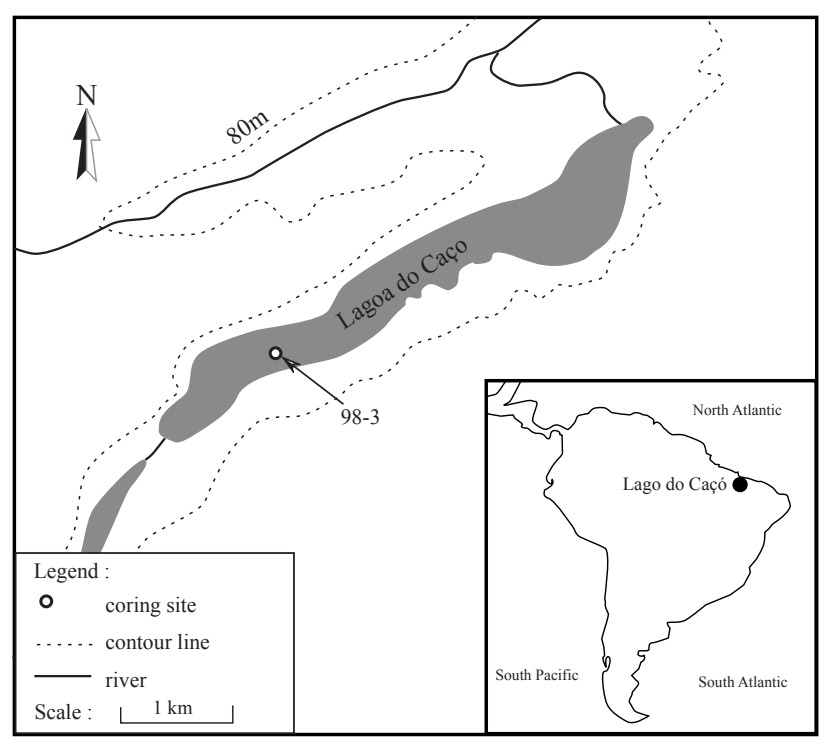

Figure 1 


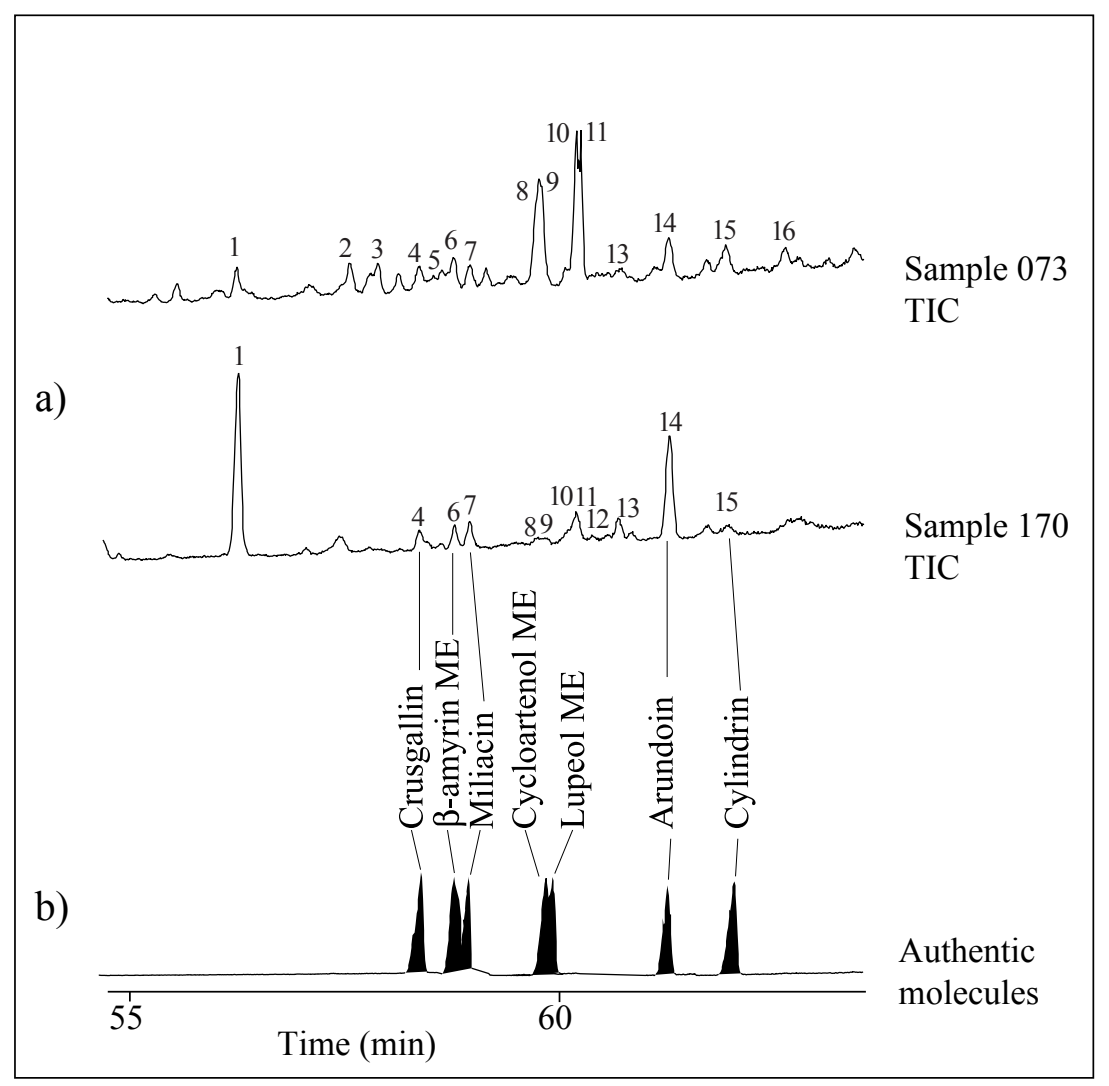

Figure 2

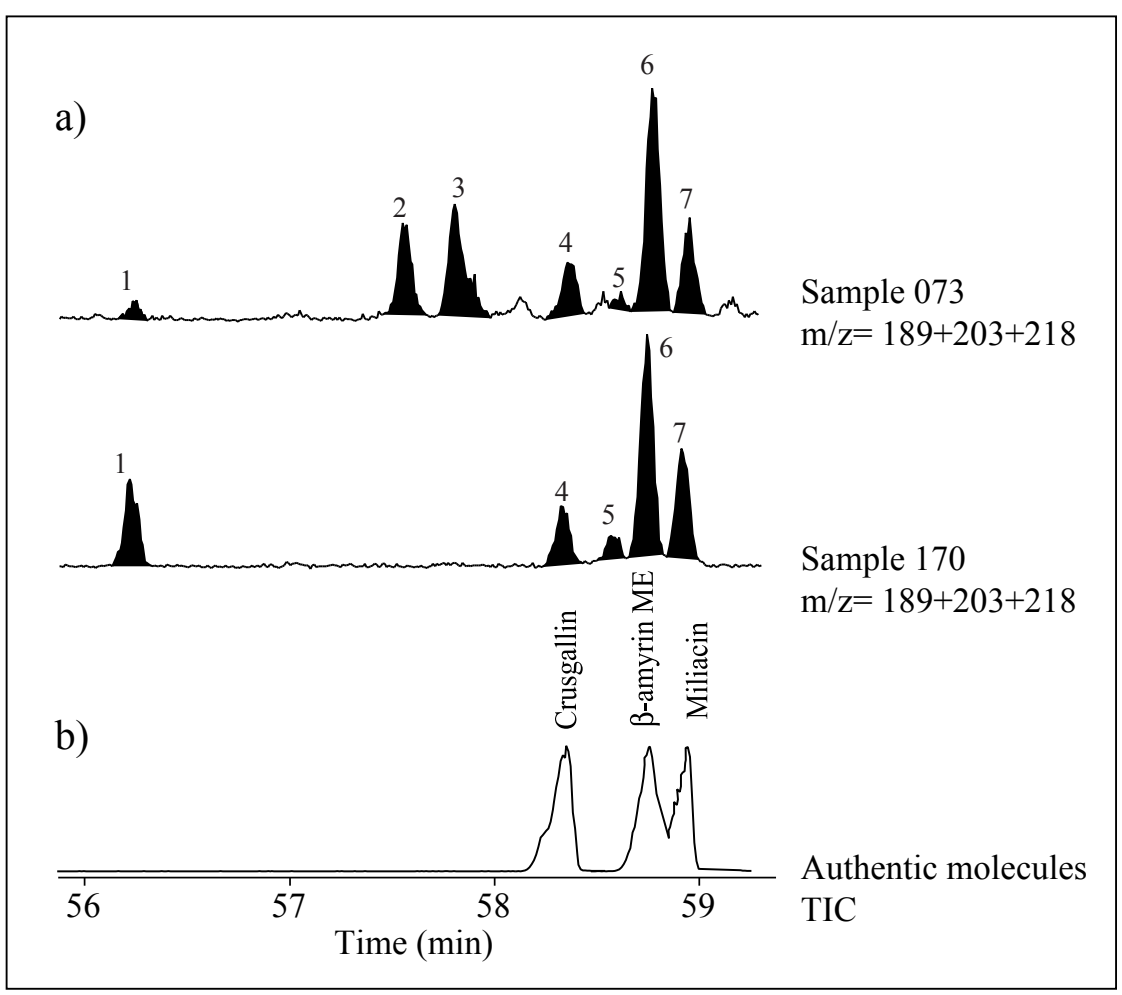

Figure 3 
Figure 4

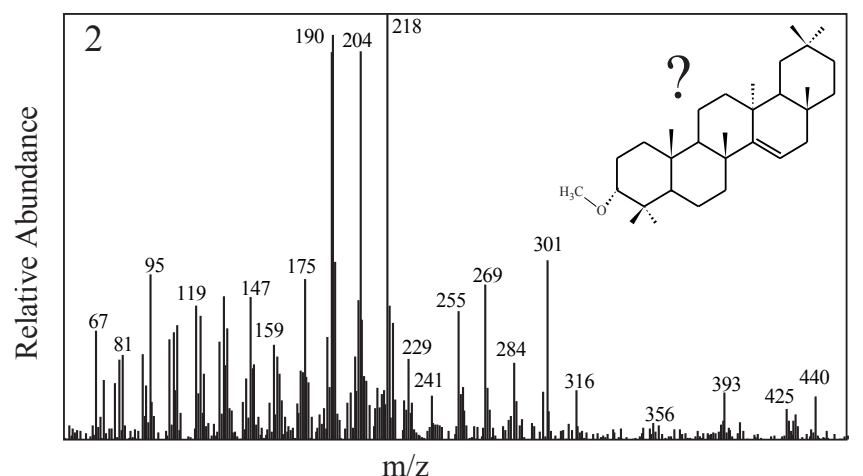

$\mathrm{m} / \mathrm{z}$

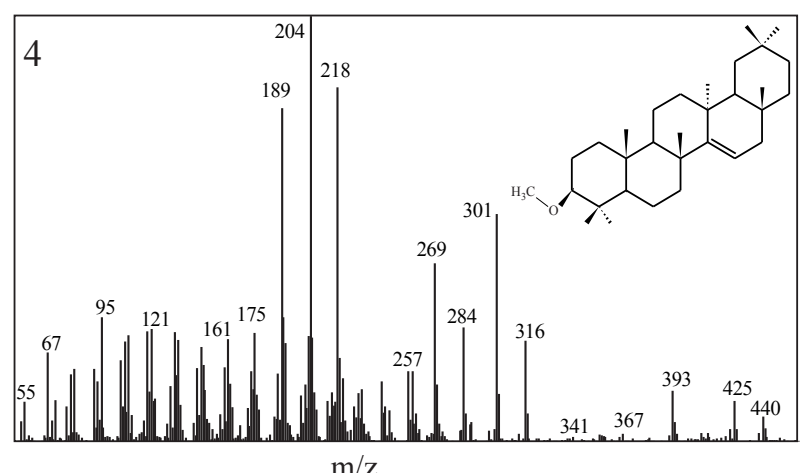

$\mathrm{m} / \mathrm{z}$
Figure 5

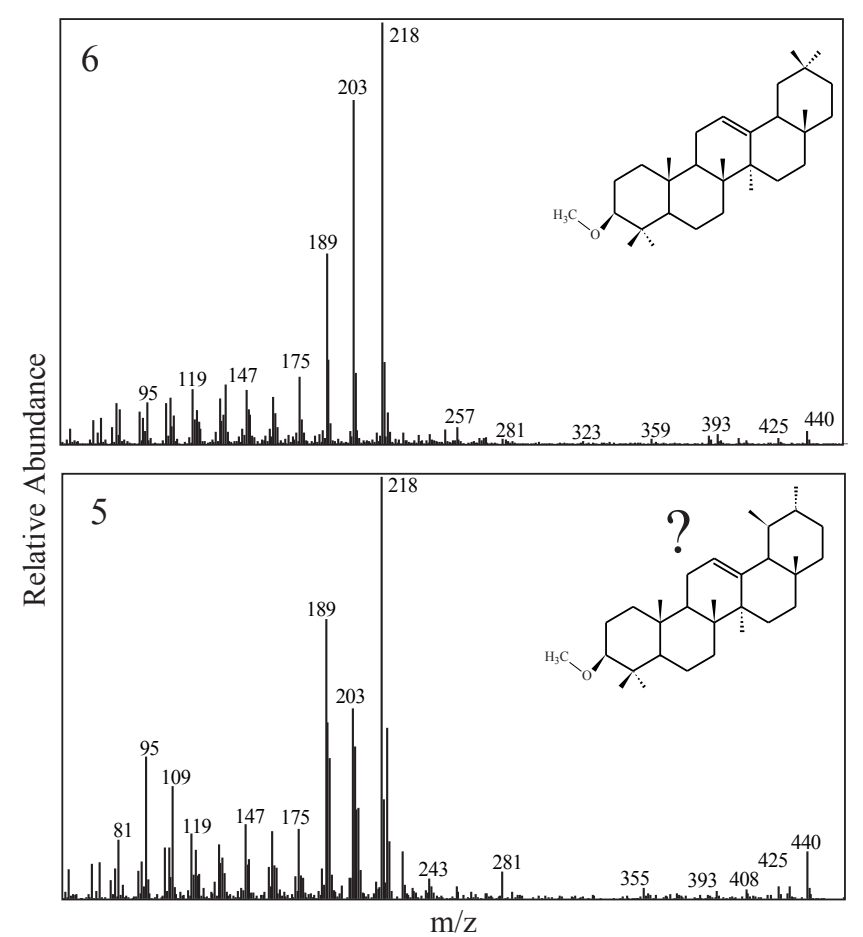

Figure 6

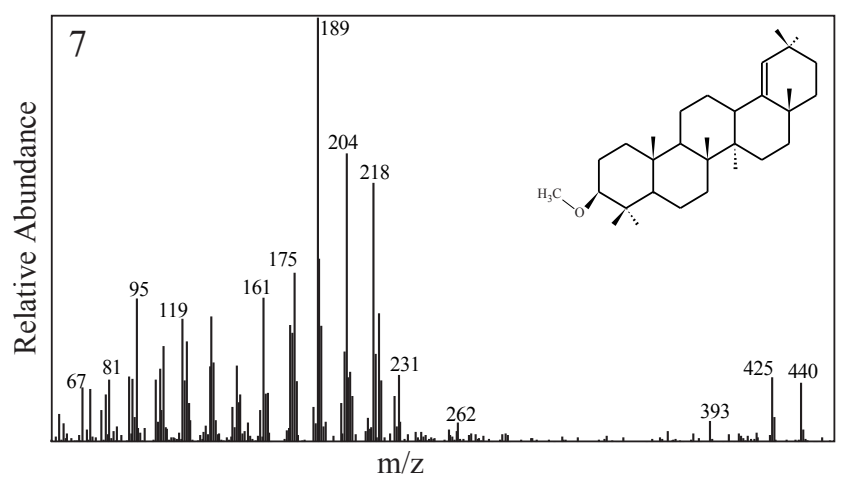

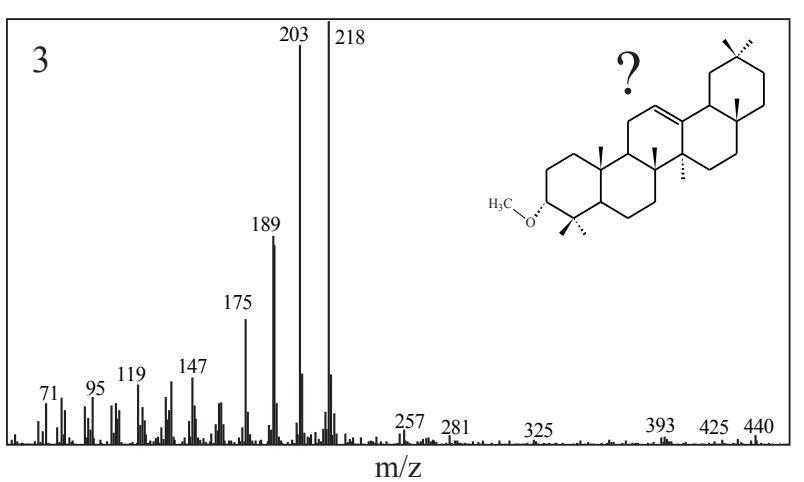




\section{Figure 7}

a) Sample 073

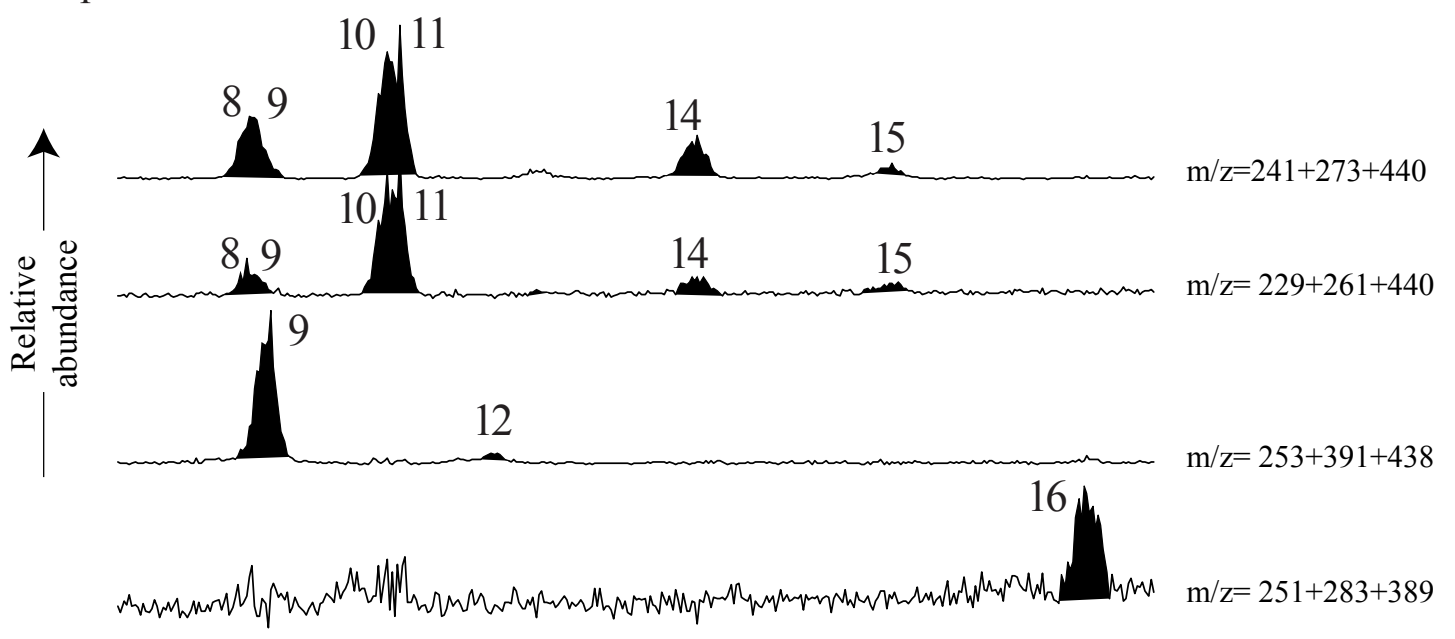

b) Sample 170

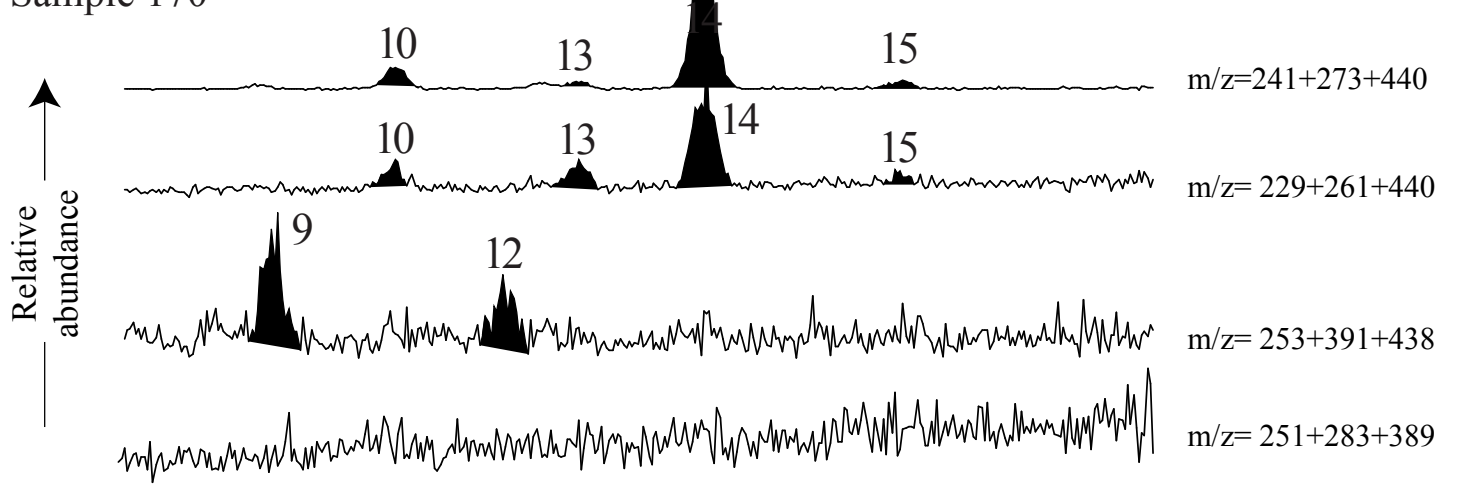

c) Authentic molecules

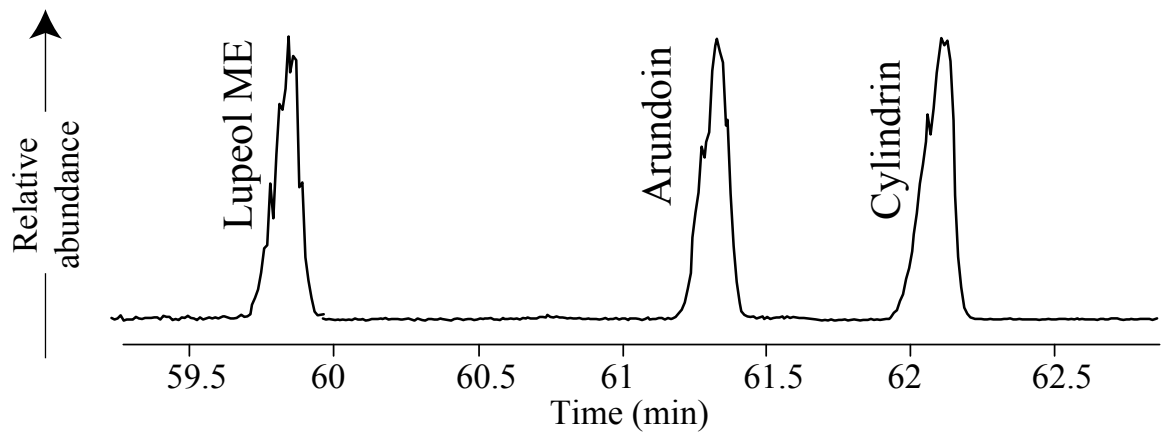


Figure 8
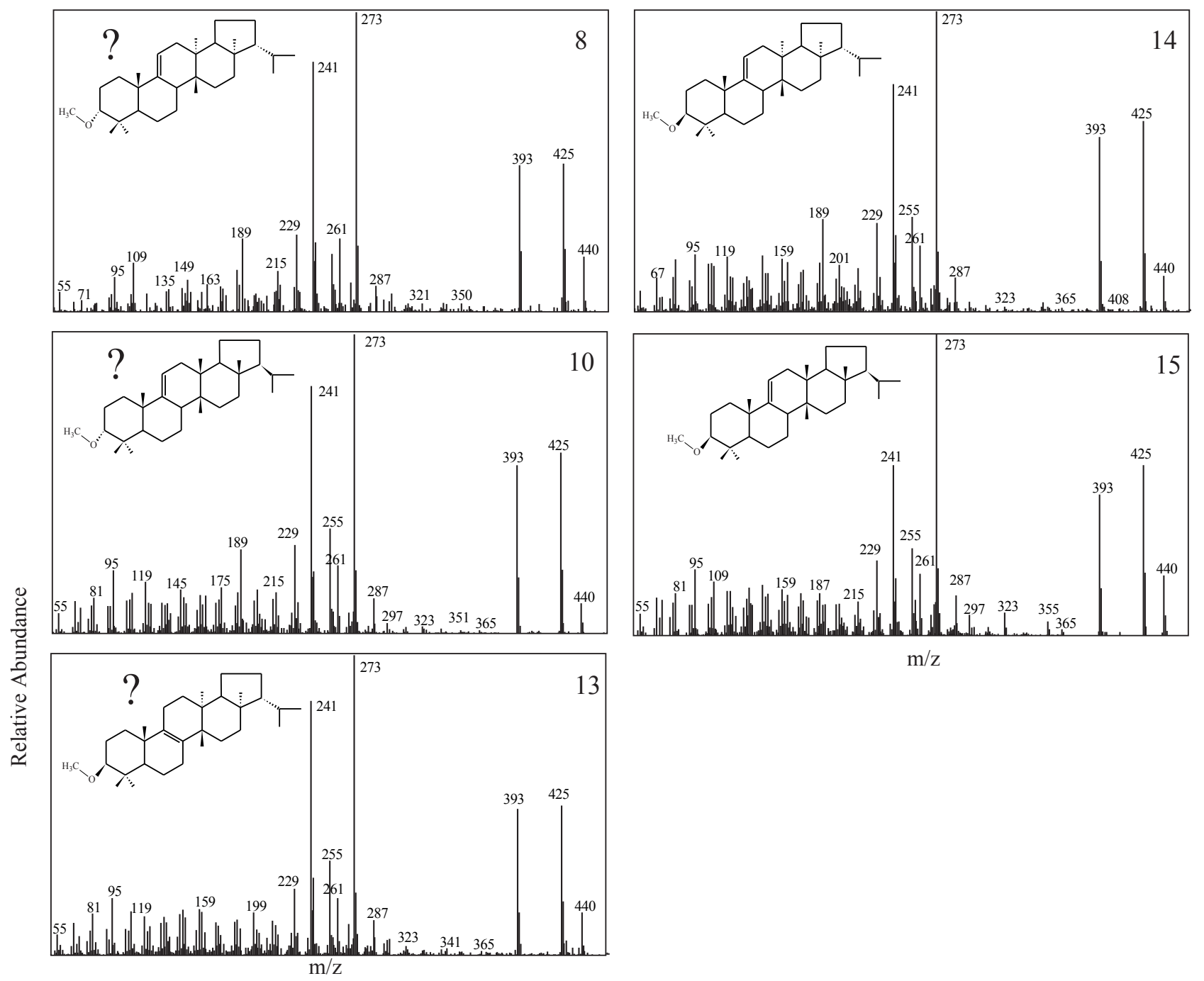
Figure 9

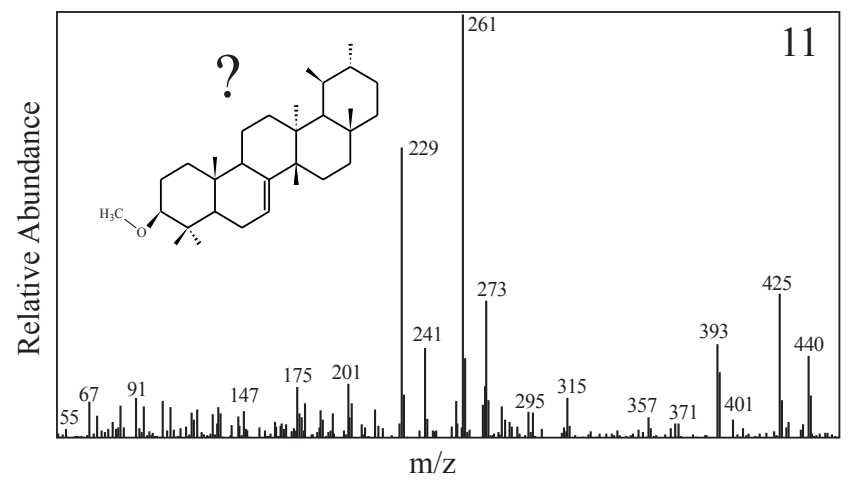

Figure 10

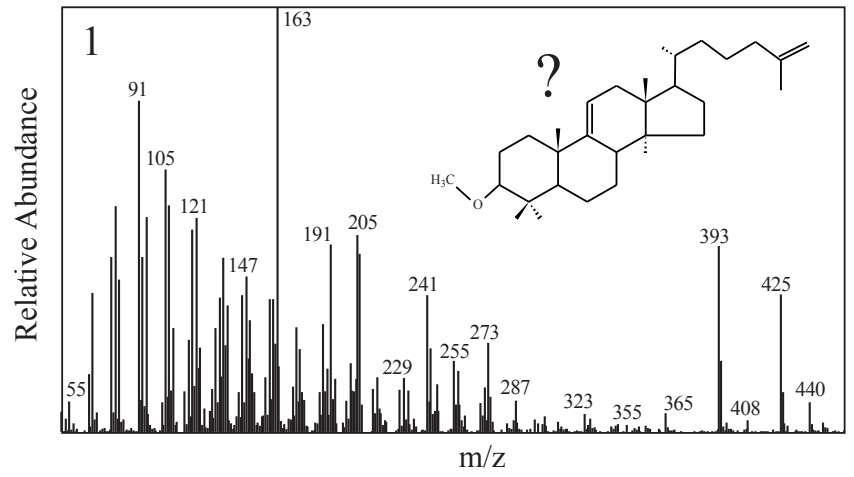

Figure 11
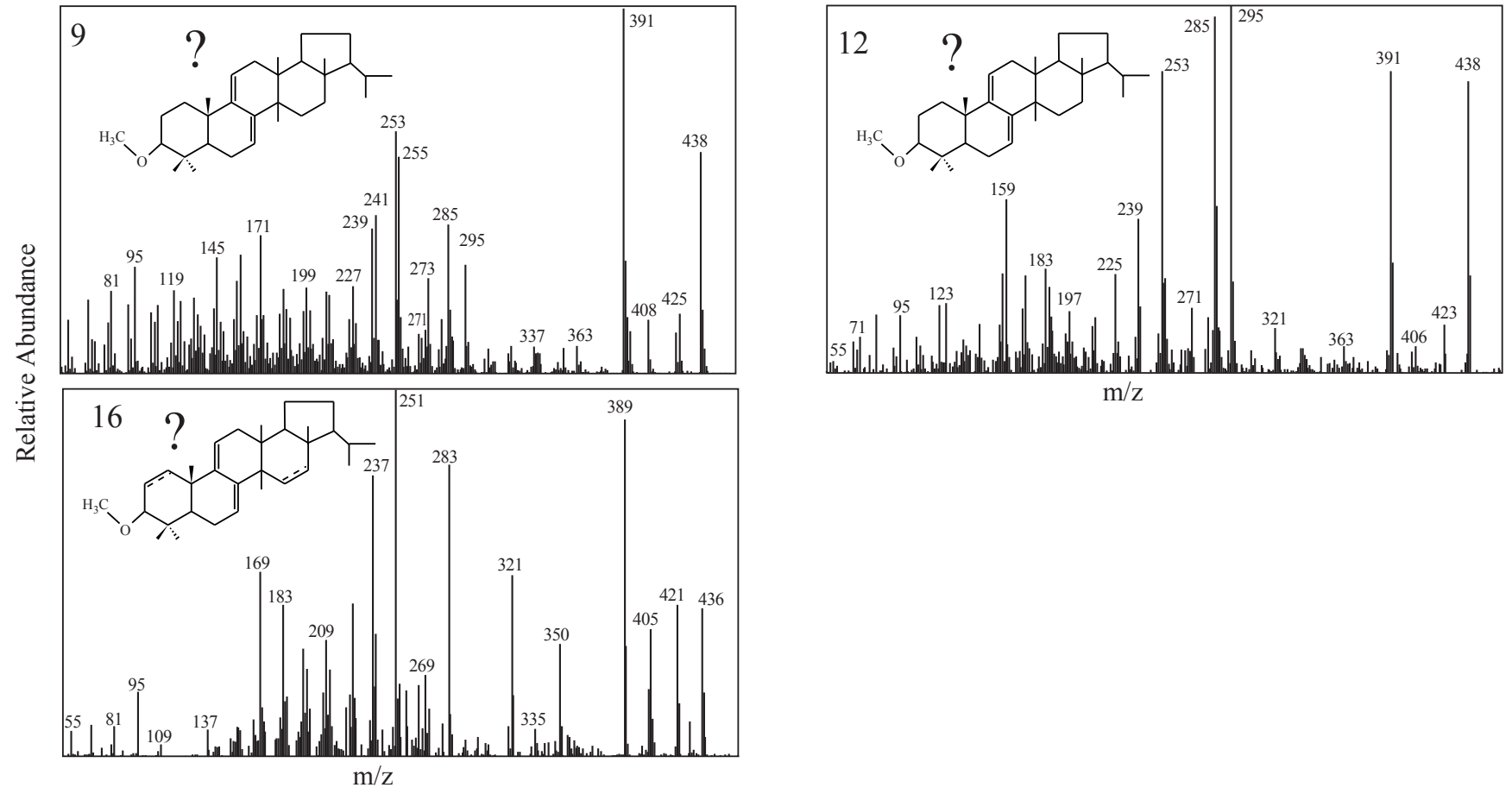